\title{
Professor C Sivagnanasundram
}

Professor Chellathurai Sivaganasundram, Emeritus Professor of Community Medicine, University of Jaffna passed away on 4 June 2005, after making valuable contributions as a medical professional, an academic, a teacher, a researcher and above all, a kind and considerate human being.

He obtained the MBBS degree from the University of Ceylon in 1955 and served in the state health services in many posts until 1964, when he joined the Department of Preventive and Social Medicine in the Faculty of Medicine, University of Ceylon at Peradeniya. In 1967, he obtained the DPH (London), and was awarded the PhD from the University of London in 1971. He was conferred an honorary DSc by the University of Jaffna in 1995.

At the Faculty of Medicine, Peradeniya, he continued his services as an excellent teacher, a mentor to students, and an active member of the faculty staff for many years until 1978, when he moved to the newly established Faculty of Medicine at the University of Jaffna as Professor of Community Medicine. He held this post until his retirement and continued to serve in this capacity for 12 years after he formally retired from university service.

His contributions to the Faculty of Medicine, Jaffna were wide and varied. He served as the Dean of the Faculty and as a member of the University Council for 14 years. The booklet titled 'Memories of our late Prof. Sivagnansundram' published by the Medical Students Union of the Faculty of Medicine, Jaffna, two months after his demise amply demonstrates their sentiments.

His contributions to education were not limited to medical professionals. His keen interest and the ability to teach different categories of paramedical staff, in the context of their role in the health system, and the practical outlook with which he conducted such training were much appreciated. These contributions were recognised even internationally and his 'Guidebook for Paramedics' has been translated to Arabic.

It would be true to say that he was a pioneer in postgraduate medical education in Sri Lanka specially in the field of Community Medicine, when he played a leading role in the organisation and conduct of the first ever postgraduate course in Community Medicine leading to the award of the degree, Master of Medical Science, by the University of Peradeniya in 1972, years before the establishment of Postgraduate Institute of Medicine. He served as a member of the Board of Study in Community Medicine of the Postgraduate Institute of Medicine for many years, until his demise. From the time of inception of the postgraduate programs in Community Medicine, he has made valuable contributions in curriculum development, as a teacher, examiner, and as a research supervisor. He provided these services with great dedication and commitment for many years.

His interest and contribution to health research, specially health systems research, earned him personal satisfaction as well as recognition from his peers and students both in Sri Lanka and outside. For nearly 14 years, he served as a Consultant in Health Systems Research to the World Health Organisation, in many countries in Asia and Africa. His book 'Learning Research' has had two editions and is widely used by both medical undergraduates and postgraduates. He has many publications to his credit and his research students have benefited much from his experience and the simple, clear manner in which he guided them.

His talents go well beyond academic contributions. He has written many novels, short stories and other books. Three of his novels have received Sri Lanka Sahithya Academy award and one novel received the Governor's (NEP) award. He has published 16 books in Tamil, on varied subjects: preventive health for lay people, for children and two on spirituality, and a handbook for teachers on Sri Sathya Sai education on human values.

For many years, he participated in health programs broadcast through mass media. He was also an actor, performing in dramas and radio dramas. During the early stages of the Tamil film industry in Sri Lanka, he acted in a lead role in a Tamil film.

He was a man of diverse capabilities. His excellence as a teacher, his commitment to the medical profession in general and Community Medicine in particular, the valuable contributions to the institutions in which he served and his attention to detail, practical outlook in his relationship with persons from all walks of life, made him an outstanding member of our profession.

Dulitha Fernando, Senior Professor of Community Medicine, Faculty of Medicine, University of Colombo, Sri Lanka; e-mail: <dulithafernando@hotmail.com> 